\title{
A suspected bronchial carcinoma
}

\section{Case report}

A 68-year-old male patient, who was an ex-smoker of 20 cigarettes a day and a retired welder, presented to his general practitioner with a 4-day history of sweats, significant weight loss of almost $13 \mathrm{~kg}$, no appetite and feeling tired, with a productive cough, phlegm and significant haemoptysis. His past medical history included an 8-year history of chronic obstructive pulmonary disease (COPD), 60 years of asthma, tuberculosis (TB) diagnosed and treated in 1974, a 15-year history of anxiety, a 16-year history of herpes zoster, and excision of a lesion from the facial bone in 2002 for a suspected melanoma. His medications included a salmeterol inhaler (Seretide 500BD; GlaxoSmithKline, Brentford, UK), tiotropium, amiodarone, carbocisteine, omeprazole and simvastatin, and due to his recurrent chest infections, he was treated with appropriate courses of antibiotics.

The patient was referred to the respiratory team at the district hospital in Glasgow, UK, for further investigation under suspicion of bronchial carcinoma.

\section{Examination}

The patient's vital signs were within normal limits and there was no finger clubbing. There were no significant chest signs. His lung function showed a forced expiratory volume in $1 \mathrm{~s}(\mathrm{FEV} 1)$ of $1.71 \mathrm{~L}$, which was $52 \%$ of predicted. His best forced vital capacity (FVC) was $3.91 \mathrm{~L}$ (92\% predicted) and best $\mathrm{FEV}_{1} / \mathrm{FVC}$ was $44 \%$, and his gas diffusion was reduced at $47 \%$ when corrected for ventilation. $A$ number of investigations were ordered in order to identify why the patient had these symptoms and to exclude cancer.

\section{Investigations}

A chest radiograph, computed tomography (CT) of the thorax with contrast, a CT-guided biopsy, a bronchoscopy and a positron emission tomography (PET)-CT scan were ordered.

\section{Task}

1. What are the abnormalities on the chest radiograph (figure 1 ) and what else do you see?

2. Discuss the abnormality in figure 2 .

3. Discuss the abnormalities on the CT scan (figure 3).
Cite as: Korsavva SG, Roy $\mathrm{S}$. A suspected bronchial carcinoma. Breathe 2017; 13: e114-e120. 


\section{Answers}

1. There is evidence of old healed TB with bilateral apical pleural thickening and calcification extending throughout the right upper zone. Lung field show background pattern consistent with COPD but show no evidence of focal active lung disease.

2. There is an ill-defined focus of shadowing seen in the left upper lobe, which was not present on the previous film and is suspicious for malignancy. Evidence of old TB is seen with bilateral apical pleural thickening and calcification. Background changes of COPD persist. The patient was referred to the specialist under the suspicion of cancer. Calcific opacities and scarring in both upper zones is in keeping with old TB disease. There is increased interstitial shadowing with septal lines at both bases but no evidence of any central masses or cardiac enlargement.

3. A mass and emphysema can be seen.

The plain film abnormality corresponds to a $3 \times 1.4-\mathrm{cm}$ focus of soft tissue attenuation within the left upper lobe. This mass is suspicious of primary bronchial carcinoma. Multiple other tiny, noncalcified nodules are present throughout the lungs, particularly within the right upper zone, which may be related to background fibrosis.

A bronchoscopy was performed in August 2011. The bronchial sample showed mixed inflammatory cells, numerous alveolar macrophages and some occasional benign bronchial epithelial cells. However, no malignant cells were found.

A CT-guided lung biopsy in September 2011 showed marked fibrosis, abundant haemosiderinladen macrophages, patchy chronic inflammatory cell infiltrates and multinucleated giant cells in places. These changes were consistent with postinflammatory or post-infarct processes but not malignancy.

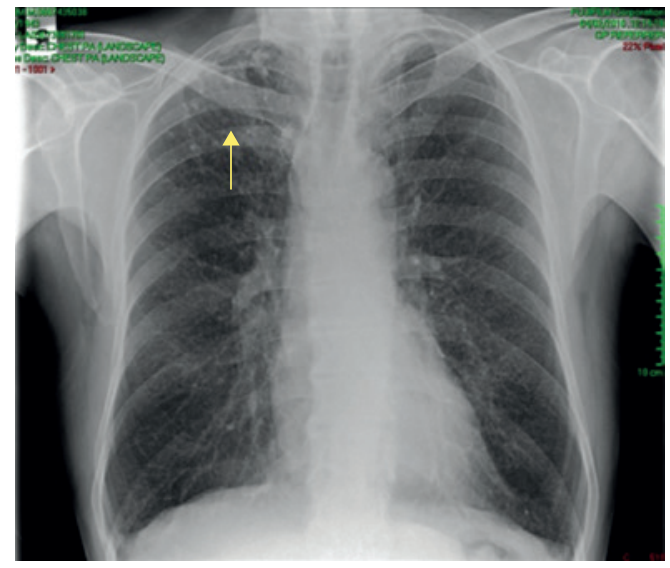

Figure 1 Baseline chest radiograph, February 2010.

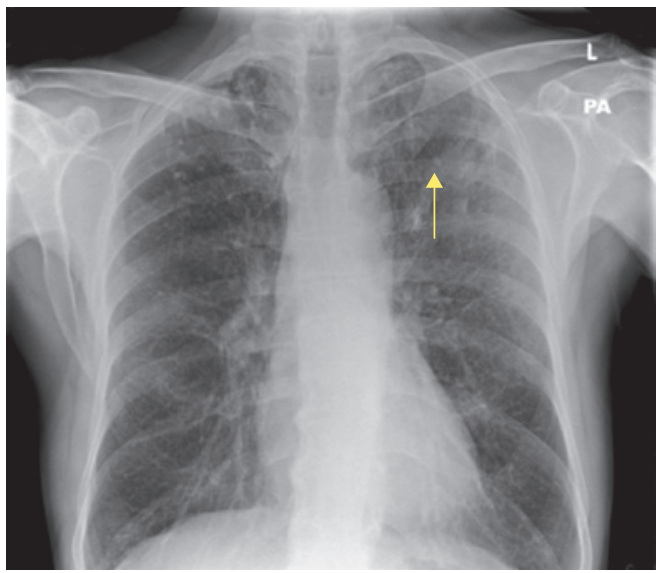

Figure 2 Repeat chest radiograph in 2011.

Following the suspicious mass detected on CT, a fluorodeoxyglucose (FDG)-PET scan was performed from the skull base to mid-thigh level (figure 4). The PET scan showed a $3.2-\mathrm{cm}$ linear but speculated lesion in the apicoposterior left upper lobe strongly suspicious of malignancy. In addition there was a short linear band opacity lying posteriorly to the descending thoracic aorta at the T7 level. In the structural imaging, this lesion appeared benign; however, the paravertebral subpleural component exhibited marked FDG activity consistent with malignancy. If malignancy was confirmed, then it would have been very likely that there was T4 disease with an ipsilateral metastasis in a separate lobe. The FDG-PET scan suggested a probable staging of T4 NO MO.

In view of these results, the decision was made to proceed with a left upper lobectomy and left lower lobe wedge resection in 2012. The patient agreed and the surgery went ahead.

Post-lobectomy, chest radiography (figure 5) showed volume loss in the left lung consistent with a left upper lobe lobectomy. There was a small left apical pneumothorax and the right lung was slightly hyperexpanded. In addition, there was evidence of fibrocalcaneus change in the right upper lobe. Both lungs showed background changes of COPD. There was no focal pulmonary disease.

Histological examination after the lobectomy showed no evidence of malignancy. Instead, it showed marked evidence of welder's lung (figure 6).

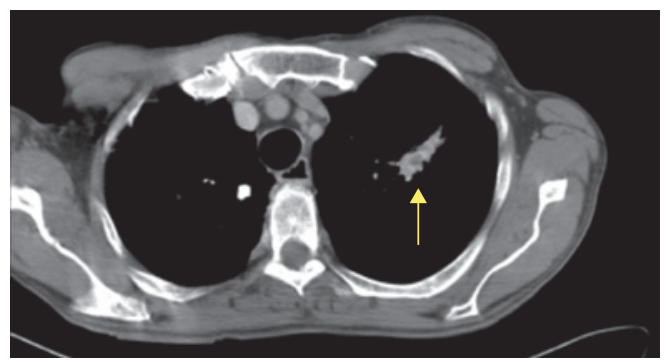

Figure 3 CT scan, August 2011. 


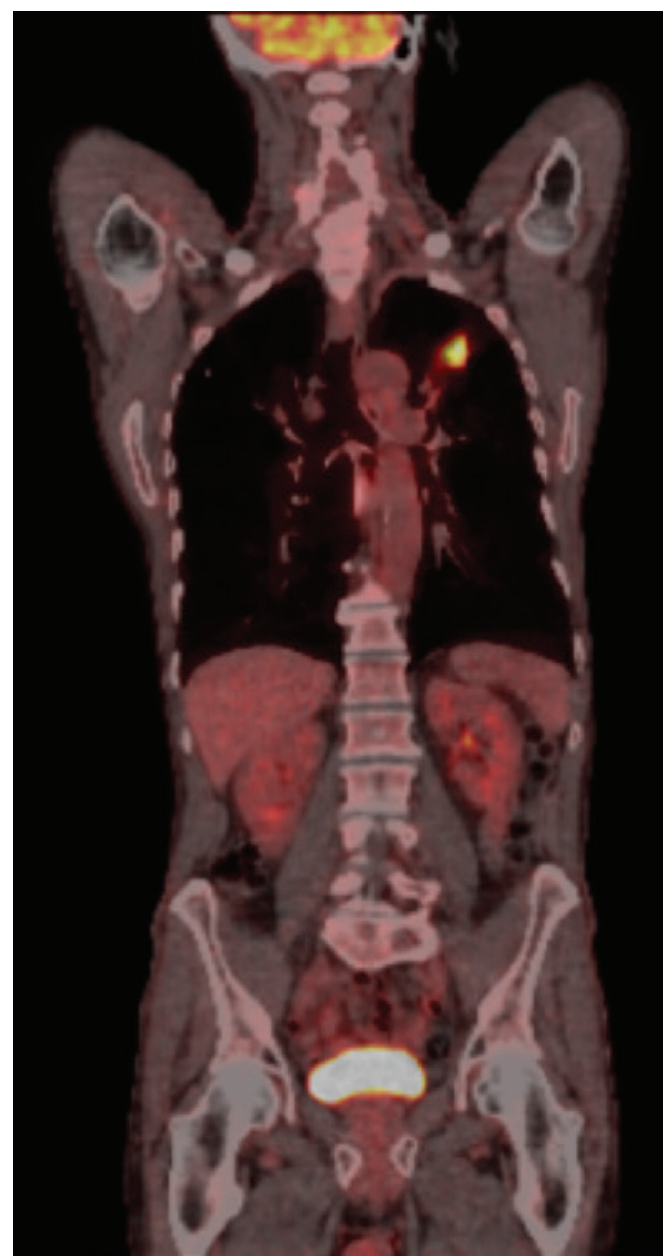

Figure 4 Initial PET-CT scan showing "hot spots".

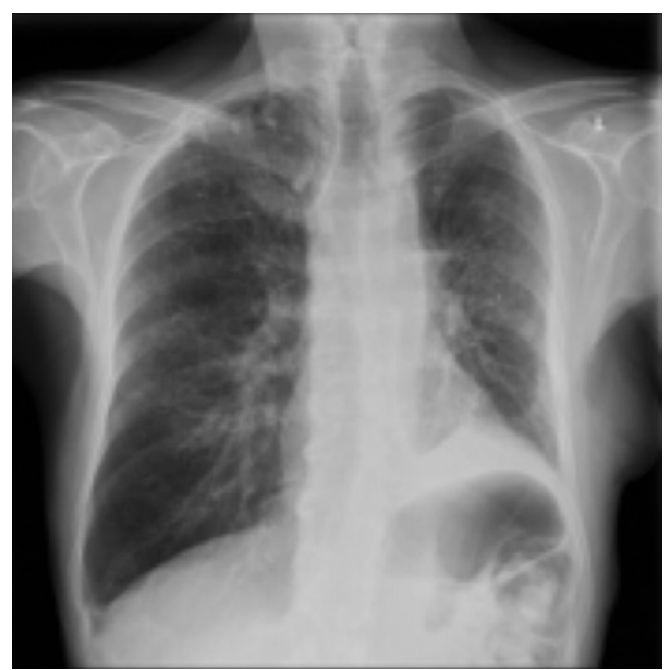

Figure 5 Post-lobectomy chest radiograph.

The patient presented to the respiratory team again in September 2012 with shortness of breath and feeling generally unwell. His pulmonary function tests showed a best FVC of $2.62 \mathrm{~L}$ (62\% predicted) and best FEV1/FVC of $46 \%$. Bronchial washing showed a light growth of Escherichia coli. He had another CT of the thorax that showed a new cavitating mass in
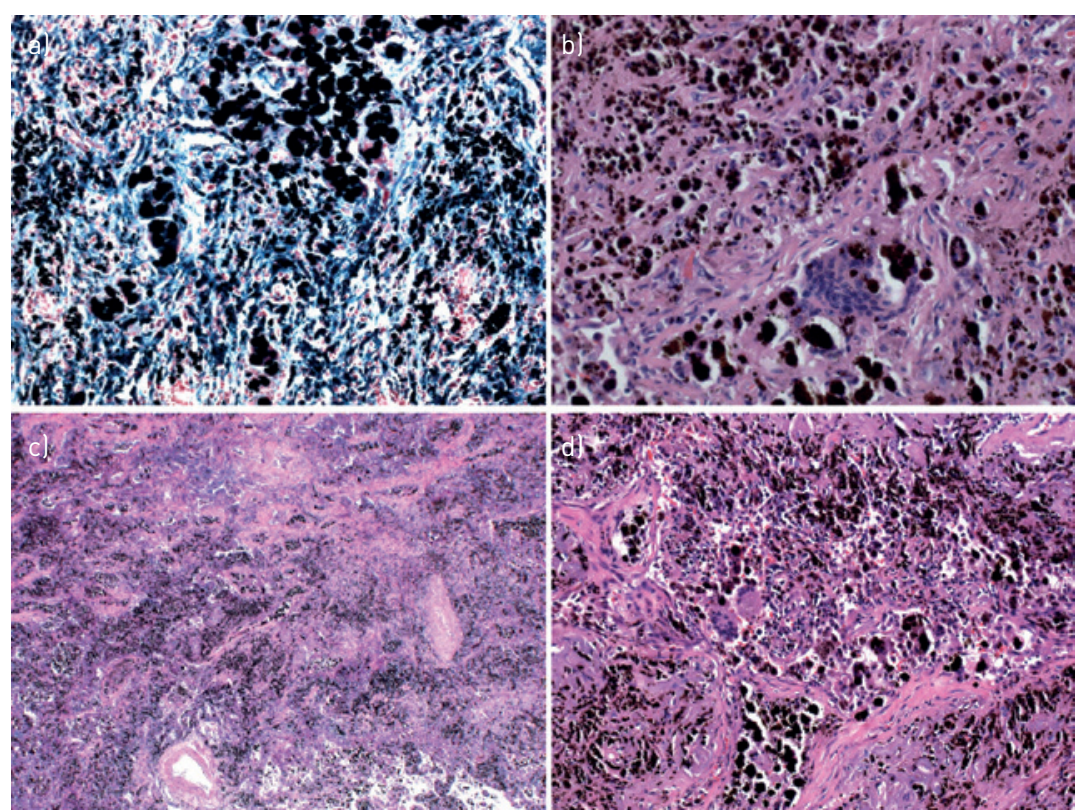

Figure 6 a) Iron stain showing welder's lung and various lung segments consistent with welder's lung changes: fibrosis with carbon and iron pigment. b) Lung tissue with scarring, abundant histiocytes and multinucleated giant cells containing pigment both iron and carbon. The alveoli contain numerous macrophages and chronic inflammatory cells. At higher magnification, there is dystrophic calcification and ossification. $c$ and d) Lymph nodes with a lot of pigment deposition but no evidence of malignancy.

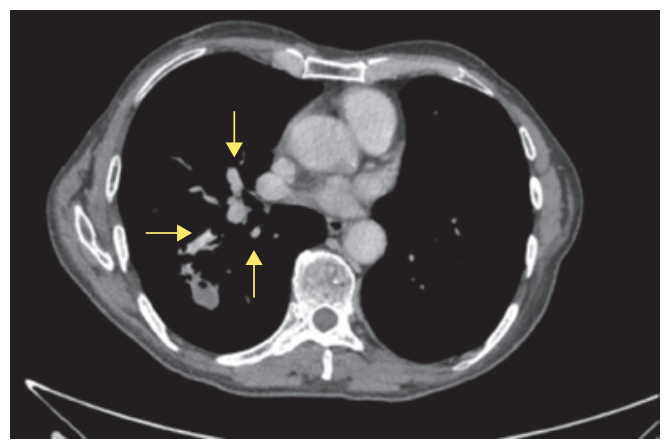

Figure 7 CT scan, September 2012. Several new lung masses can be seen. There is a cavitating soft tissue mass measuring $2.5 \times 1.9 \mathrm{~cm}$ within the right lower lobe with adjacent consolidation and inflammatory changes. There is a further mass within the left upper lobe measuring $1.3 \mathrm{~cm}$. No other sizeable intrapulmonary mass lesions are seen. A precarinal node measures $9 \mathrm{~mm}$ in the short axis. These are highly suggestive of malignancy.

the right lower lobe, an adjacent consolidation or inflammatory change extending to the oblique fissure and a further mass in the left upper lobe, again highly suggestive of neoplasms (figure 7).

The patient was discussed in the multidisciplinary team (MDT) meeting, and another bronchoscopy, another PET scan and a further MDT review were planned.

The follow-up PET scan could not exclude neoplasia; however, the lesion of the right lower lobe had reduced in size suggesting it might have been inflammatory (figure 8). The low-level uptake within the lesion superiorly in the left upper lobe suggested it could be benign granulomatous, rather than neoplastic, lesion. 


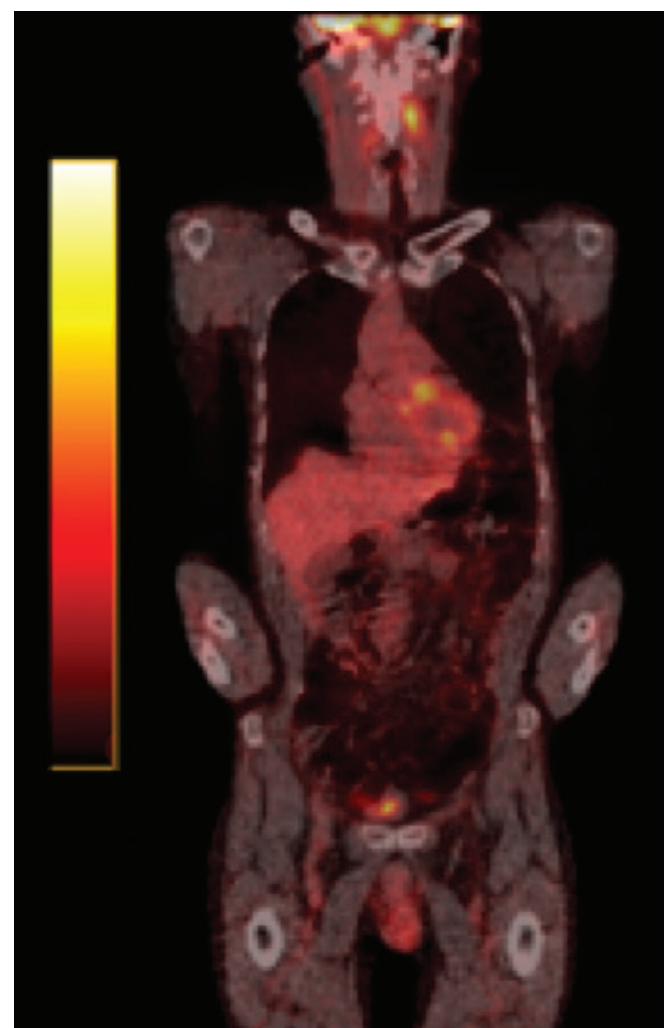

Figure 8 Follow up PET-CT scan.
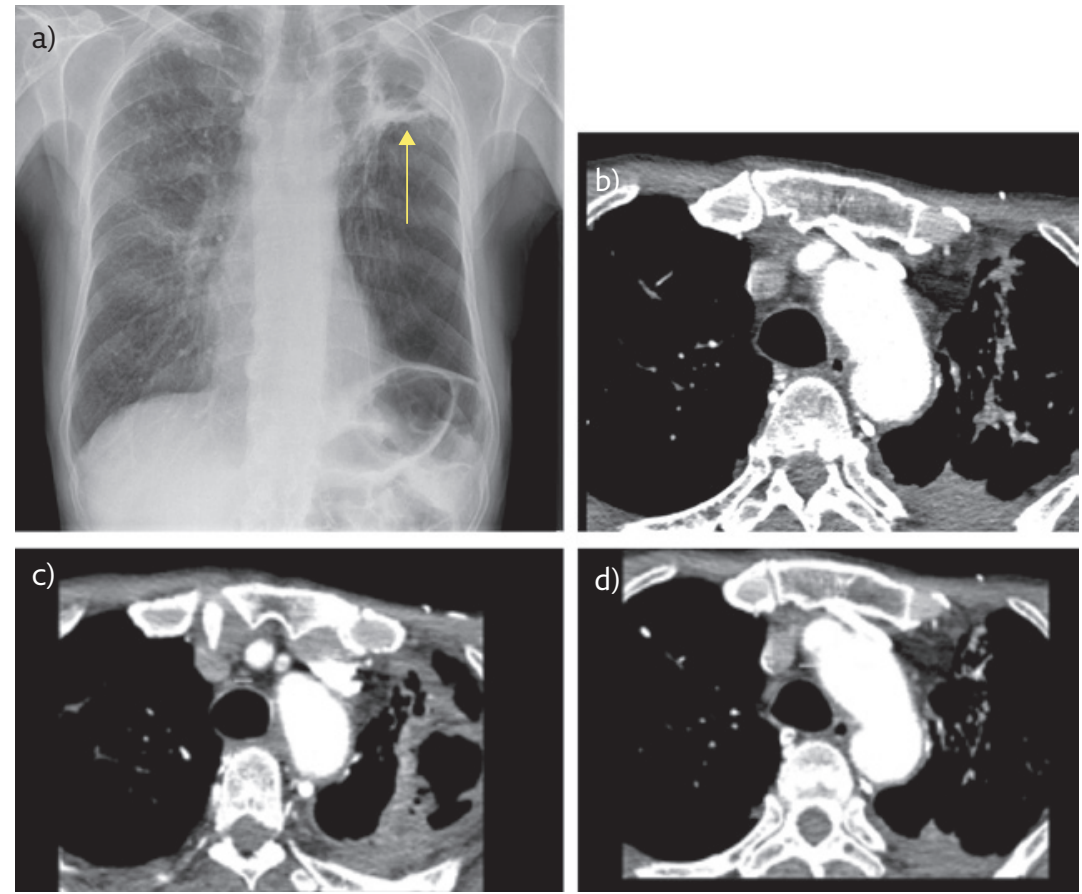

Figure 9 a) Chest radiograph (2016) of the patient showing areas of old TB disease (arrow). $b-d)$ Thoracic CT thorax snapshots showing areas of marked fibrosis.

The MDT decision was to repeat CT of the thorax at the beginning of January 2013. The January CT scan did not show any changes, nor did the scans in 2014.

In 2015, a year later, the patient presented to the respiratory clinic again with new symptoms. On

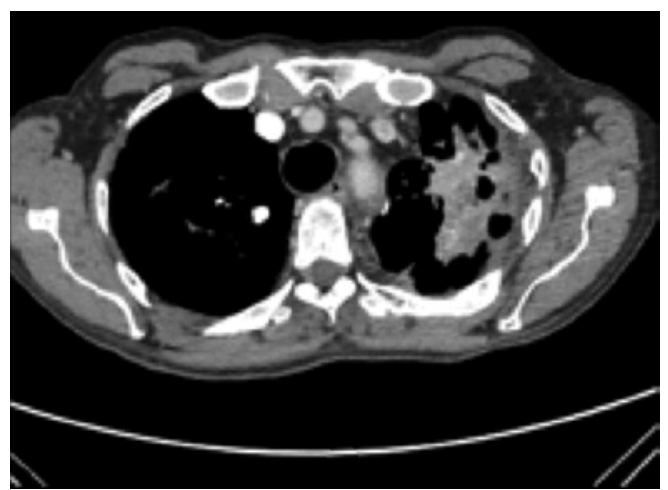

Figure 10 CT scan, June 2015. There is a thick-walled cavity in the left apex at the site of the previous bulla that incorporates the previously noted 1.5 -cm soft tissue nodule.

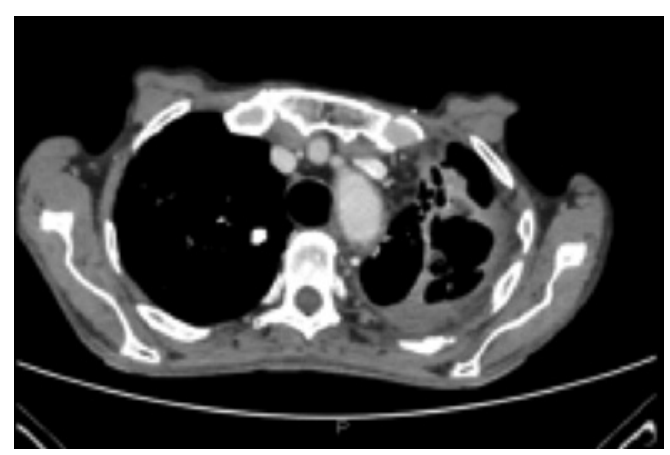

Figure 11 CT scan with contrast, 2016. A further increase in the cavitation in the left upper zone with marked related emphysema in the residual left lower lobe can be seen.

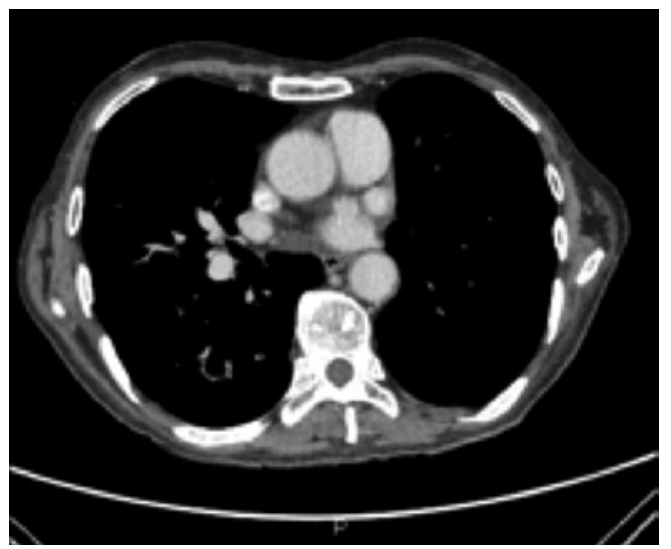

Figure 12 CT scan, June 2105. A cavitating lesion can be seen in the right lobe.

examination he had a cough, which sounded dry and hacking. His body weight was $59.2 \mathrm{~kg}$ with normal blood pressure and pulse, and oxygen saturation of $93 \%$ breathing in room air. Chest auscultation revealed mild wheeze. A repeat chest radiograph was performed that showed an ill-defined focus of shadowing in the left upper lobe suspicious of malignancy: a thick walled irregular cavity at the left apex that had increased in size (figure 9a). A CT of the thorax with contrast was subsequently ordered to investigate further (figure $9 b-d$ ). 


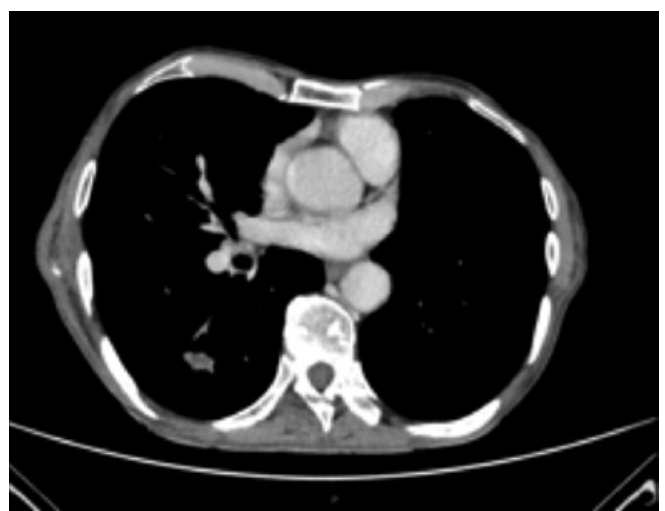

Figure 13 CT scan, October 2016. The lesion has now become a spiculated nodule.

In 2015, the patient was considered for longterm oxygen therapy but blood gas analysis on air showed hydrogen ion $35 \mu \mathrm{mol} \cdot \mathrm{L}^{-1}$, carbon dioxide tension $3.6 \mathrm{kPa}$ and oxygen tension $14.6 \mathrm{kPa}$, base excess $-4.1 \mathrm{mEq} \cdot \mathrm{L}^{-1}$, and bicarbonate $19 \mathrm{mEq} \cdot \mathrm{L}^{-1}$, with oxygen saturation at $97 \%$. As such, it was decided that he did not actually need it.

The respiratory team decided to keep monitoring the patient, and repeat chest radiography and CT. Those were repeated in 2015 (figure 10) and 2016 (figure 11) but unfortunately showed significant changes.

The previous cavitating lesion in the right lower lobe (figure 12) became a $10 \times 15-\mathrm{mm}$ spiculated nodule (figure 13). These appearances could represent an inflammatory scar or a slow-growing bronchial carcinoma.

A full blood count showed haemoglobin 12.2 $\mathrm{mmol} \cdot \mathrm{L}^{-1}$, white cell count 10 , platelet count $520 \times 10^{9}$ per L, C-reactive protein $54 \mathrm{~g} \cdot \mathrm{L}^{-1}$, and normal liver, kidney and thyroid function tests. The CT scan showed that the nodules at the right lung apex and prominent interstitial markings throughout the right lung had not changed. His recent sputum sample did not show any microbes

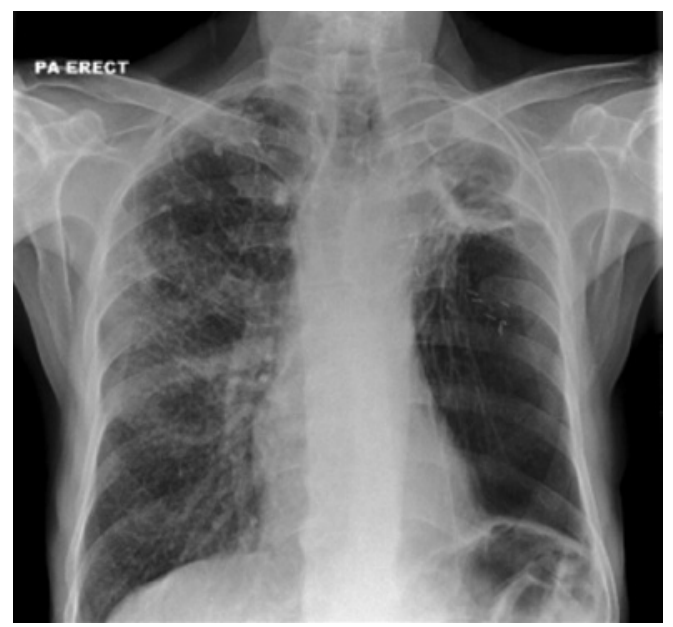

Figure 14 Latest chest radiograph. or AAFB, although in the past there was an AAFB infection at some point.

At the end of May 2016, the patient had an elective bronchoscopy that only showed inflammatory cell infiltrates and no malignancy. Latest chest radiograph (figure 14) showed an irregular focus of increased density peripherally within the right mid-zone, which could be inflammatory or because of another cause.

In April 2016, the patient was hyperthyroid and had lost a lot of weight; he weight $49 \mathrm{~kg}$. His thyroid function showed free thyroxine $28 \mathrm{pmol} \cdot \mathrm{L}^{-1}$, free triiodothyronine $8.6 \mathrm{pmol} \cdot \mathrm{L}^{-1}$ and thyroidstimulating hormone $<0.05 \mathrm{mU} \cdot \mathrm{L}^{-1}$. He was treated with carbimazole $20 \mathrm{mg}$ once a day. He had a fineneedle aspiration of one of the small glands on the left side of his neck that only showed inflammation and nothing else.

\section{Discussion}

According to the 2016 Health and Safety Executive report, there are 12000 deaths every year because of occupational respiratory disease in the UK. About two-thirds are COPD or asbestos related. In 2015, 36000 people who started work developed occupational respiratory disease and 141000 that had already been working had been suffering as well. It is estimated that every year, there are 14000 new cases of new-onset lung diseases that are made worse or are caused by work-related reasons [1].

Welder's lung, also known as lung siderosis or iron lung, is an occupational lung disease in the category of chronic lung diseases known as pneumoconiosis. It is caused by the inhalation of iron particles and iron oxide that are in the fumes produced during welding. These iron deposits in the lung cause tissue reactions that, if chronic, can cause lung scarring and respiratory disease [2]. Similar presentations are produced by the inhalation of tin (stannosis) and barium (baritosis). The iron oxide absorbs the $\mathrm{X}$-rays during chest radiography and can produce shadows that may indicate serious pathology. Most researchers agree that lung siderosis is a benign lung disease; however, if complications occur, patients are known to present with recurrent chest infections, pulmonary fibrosis, chronic obstructive lung disease [3], or neoplasms and lung cancer [4-7].

The approach to investigating a patient who is suspected of suffering from an occupational lung disease is stepwise. It is very important to take a careful occupational history, auscultate the patient's chest, and perform spirometry and lung function tests. To begin, chest radiography is required, then a sputum culture, and a CT of the thorax with contrast and/or a high-resolution CT scan; if needed, bronchoscopy, a CT-guided biopsy and, finally, a PET-CT scan should be performed if malignancy is suspected. It is essential to refer the 
patient to a respiratory specialist, who can decide all aspects of patient management, investigations and treatment. The legal aspects must carefully be considered; for example, in the UK, depending on whether the patient is in England, Scotland, Wales or Northern Ireland, different laws apply [8].

Siderosis was first described in 1936 by DoIc and MCLauglin [9]. However, it was in 1867 that ZENKER [10] discussed the discovery of iron oxide in the lungs of welders. Inhaled iron particles are usually removed by the sputum; however, in the case of iron welders, this is not enough, as they are exposed on a daily basis to those particles and so these cannot adequately be removed this way. As a result, they accumulate in the lungs and can cause a number of conditions, as previously discussed. Interestingly, lung siderosis can also be caused by other substances, such as powdered haematite, magnetite and limonite. It has been observed not only in welders and miners but also polishers that use iron oxide to polish silver or steel. It is believed that lung siderosis was much more common in ancient Egypt, where labourers and sculptors worked with powdered haematite. Siderosis also occurs in the cardiovascular system [11], either as a result of thalassaemia major, or because of recurrent blood transfusions for anaemia or other reasons. It is also associated with fibrotic changes and interstitial fibrotic changes, although some studies debate whether replacement fibrotic changes in the cardiac tissue are indeed present $[11,12]$.

An interesting study by Coscrove [13] has linked steel welding fumes with occupational respiratory bronchiolitis, which may or may not result in interstitial pneumonia if there is ongoing exposure. Ongoing inflammation from recurrent upper and lower respiratory tract infections combined with pulmonary scarring can perhaps explain why iron welders are at an increased risk of cancer [14].

Our patient worked as an iron welder for many years and because his biopsy post-lobectomy confirmed the diagnosis of welder's lung, he requested and received compensation from the company for which he used to work. His ongoing problems had a big impact on his quality of life and his ability to work.

In the case of our patient, the cavitating lesions and the bronchiectasis in the left upper lobe cannot be easily explained despite his chronic pathology. The question here is if this presentation is part of the welder's lung pathology or if it is a recurrent fungal infection that, so far, we have not been able to identify. His Aspergillus serology in March 2014 showed positive results. More specifically, it showed IgG $83 \mathrm{~g} \cdot \mathrm{L}^{-1}$ (normally $<40 \mathrm{~g} \cdot \mathrm{L}^{-1}$ ), IgE to Aspergillus m3 $0.47 \mathrm{~g} \cdot \mathrm{L}^{-1}$ (normally $<0.35 \mathrm{~g} \cdot \mathrm{L}^{-1}$ ) and total IgE $822 \mathrm{~g} \cdot \mathrm{L}^{-1}$ (normally $0-120 \mathrm{~g} \cdot \mathrm{L}^{-1}$ ). The relationship between Aspergillus and welder's lung can be a consequence of the patient's comorbidities and weakened immune system. On some occasions, COPD patients may show positive serology for Aspergillus but it is not possible to establish whether aspergillosis was manifested because of COPD or because of welder's lung. In either case, however, it was decided that no treatment was necessary for this particular patient.

The treatment for welder's lung is usually symptomatic. Recent studies have shown that diseases of the pneumoconiosis group can be detrimental to cardiovascular health, with patients presenting with heart failure [15] and cerebrovascular events [16]. This patient has not had any cardiovascular or cerebrovascular events so far. His respiratory problems are ongoing and he is under the care of a consultant respiratory physician; however, to fate, no malignancy has been identified despite all the ongoing findings in his lungs.

\section{Conclusion}

Although welder's lung can be of a benign nature, it has been loosely associated with malignancy, and more so with pulmonary fibrosis and ongoing respiratory problems such as recurrent respiratory infections, pulmonary fibrosis, asthma and COPD. Treatment is symptomatic and most patients receive asthma or COPD treatment, as these are usually always present in patients with lung siderosis. Evidence-based medicine is invaluable to steer physicians in the right direction for comorbidity prediction and treatment; however, this is not necessarily always the case. Our patient had multiple respiratory problems and it would have been very easy to believe that it was because he had bronchial carcinoma secondary to lung siderosis. However, the respiratory consultant and the MDT treated the patient and not his CT scans or radiographs. This is a valuable lesson to be learnt for all doctors who wish to improve their practice with critical thinking combined with evidence-base medicine information and clinical guidelines.

\section{Acknowledgements}

We would like to thank Navin Boniface Matthias and Alistair William Forrester (Hairmyres Hospital, Glasgow, UK) for all their valuable input and excellent work. 


\section{References}

1. Health and Safety Executive. Work-Related Respiratory Disease in Great Britain. www.hse.gov.uk/statistics/causdis/ respiratory-diseases.pdf. Date last updated: 2016.

2. Bandici RM, Bandici R, Cioban CG, et al. Lung siderosis; a review. Med Con 2015; 10: 43-47.

3. Billings CG, Howard P. Occupational siderosis and welders' lung: a review. Monaldi Arch Chest Dis 1993; 48: 304-314

4. 't Mannetje A, Brennan P, Zaridze D, et al. Welding and lung cancer in central and eastern Europe and the United Kingdom. Am J Epidemiol 2012; 175: 706-714.

5. Ambroise D, Wild P, Moulin JJ. Update of a meta-analysis on lung cancer and welding. Scand J Work Environ Health 2006; 32: 22-31

6. Simonato L, Fletcher AC, Andersen A, et al. A historical prospective study of European stainless steel, mild steel, and shipyard welders. Br J Ind Med 1991; 48: 145-154.

7. Moulin JJ. A meta-analysis of epidemiologic studies of lung cancer in welders. Scand J Work Environ Health 1997; 23 104-113.

8. Northern Ireland Courts and Tribunals Service. Court awards damages for pleural plaques. https://www.courtsni.gov. uk/en-GB/Judicial\%20Decisions/SummaryJudgments/ Documents/Court\%20Awards\%20Damages\%20for\%20 Pleural\%20Plaques/j_j_Summary\%20of\%20judgment\%20 -\%20McCauley\%20v\%20Harland\%20and\%20Wolff\%20
plc\%20and\%20Royal\%20Mail\%2027\%20Jun\%2014.htm. Date last updated: June 27, 2014.

9. Doig AT, McLaughlin AIG. X-ray appearances of the lungs of electric arc welders. Lancet 1936; 1: 771-775.

10.Zenker FA. Über Staubinhalationskrankheiten der Lungen. Dtsch Arch Klin Med 1867; 2: 116-172.

11. Beshlawy E, El Tagui M, Hamdy M, et al. Low prevalence of cardiac siderosis in heavily iron loaded Egyptian thalassemia major patients. Ann Hematol 2014; 93: 375-379.

12. Kirk P, Sheppard M, Carpenter J-P, et al. Post-mortem study of the association between cardiac iron and fibrosis in transfusion dependent anaemia. J Cardiovasc Magn Reson 2017; 19: 36

13. Cosgrove MP. Pulmonary fibrosis and exposure to steel welding fume. Occup Med (Lond) 2015; 65: 706-712.

14. Pease $C$, Rücker T, Birk T. Review of the evidence from epidemiology, toxicology, and lung bioavailability on the carcinogenicity of inhaled iron oxide particulates. Chem Res Toxicol 2016; 29: 237-254.

15. Yen C-M, Lin C-L, Lin M-C, et al. Pneumoconiosis increases the risk of congestive heart failure: a nationwide population-based cohort study. Medicine (Baltimore) 2016; 95: e3972.

16. Cheng $\mathrm{Y}-\mathrm{Y}$, Hsu $\mathrm{K}-\mathrm{H}$, Chen $\mathrm{Y}-\mathrm{H}$, et al. Increased risk of ischemic stroke in patients with pneumoconiosis. J Clin Neurosci 2015; 22: 363-367. 